\title{
A Residência Multiprofissional em Saúde como estratégia para a humanização: modos de intervir no cotidiano de um hospital universitário
}

\author{
Aline Alves Menezes ${ }^{\text {Orcid, }}$ Liliana da Escóssia ${ }^{\text {Orcid }}$ \\ Universidade Federal do Sergipe, São Cristóvão, SE, Brasil
}

\begin{abstract}
Resumo
A saúde coletiva tem se constituído como uma nova forma de conceber a saúde e a doença, produzindo mudanças nas práticas de atenção/gestão do SUS (Sistema Único de Saúde). Dentre essas mudanças, destaca-se a aposta na produção de um tipo de relação entre os sujeitos e em certo modo de trabalhar em equipe. Nesse contexto, foi criada a Política Nacional de Humanização (PNH), favorecendo a produção de espaços e práticas coletivas, dentre os quais a Residencia Multiprofissional (REMU). Este trabalho teve por objetivo acompanhar e analisar processos de criação de dispositivos consonantes com a PNH em um Hospital Universitário, a partir das intervenções produzidas pela REMU. O método utilizado foi a Cartografia, que possibilitou o mapeamento das forças presentes nas relações em que se constrói tal projeto de saúde. Através da atuação multiprofissional, criaram-se no cotidiano do hospital mecanismos de fortalecimento do SUS ao se experimentarem novos modos de cuidar e organizar os serviços.
\end{abstract}

Palavras-chave: residência multiprofissional; humanização; saúde.

\section{Health multiprofissional residence as a strategy for humanization: interventions in university hospital daily}

\begin{abstract}
The public health has been established as a new way of thinking about health and disease, producing changes in SUS (Sistema Único de Saúde - Brazil's National Health System) care/management practices. Among these changes, it highlights the focus on production of a type of relationship between the subject and a sense of teamwork. In this context, it was created the National Humanization Policy (PNH), emphasizing the production of spaces and collective practices, among these, the Multidisciplinary Residency (REMU). This study aimed to monitor and analyze processes creation of device consonants with PNH in University Hospital, as from interventions produced by REMU. The method used was Cartography, that allows to map the forces present in the relationship that is built this as health project. Activities multidisciplinary created SUS strengthening mechanisms trought new ways to care and organize the services in the hospital daily.
\end{abstract}

Keywords: multidisciplinary residency; humanization; health.

\section{Introdução}

No intuito de construir uma política de qualificação do SUS, foi criada, em 2003, a Política Nacional de Humanização (PNH). Humanizar, para esta política, requer a adoção de posturas e práticas que valorizem os diferentes atores implicados no processo de produção de saúde, estimulando neles a corresponsabilização e a autonomia, bem como a ampliação do acesso com atendimento resolutivo e a valorização do trabalhador.

A proposta fundamental do conceito é trazer uma nova concepção do humano, considerando-o em sua diversidade normativa ${ }^{1}$ e nas mudanças que experimenta nos encontros coletivos. Segundo Benevides e Passos (2005, p. 391), o sentido de humanizar proposto pela PNH con-

\footnotetext{
^Endereço para correspondência: Programa de Pós-Graduação em Psicologia d Universidade Federal de Sergipe, Cidade Universitária Prof. Aloísio de Campos, Av. Marechal Rondon, s/n, Jardim Rosa Elze, CEP: 49.100.000, São Cristóvão. E-mail: alinemenezzes@hotmail.com, lilianaescossia@gmail.com

${ }^{1} \mathrm{~A}$ ideia de diversidade normativa refere-se ao conceito de normatividade tal como definido por Canguilhem (1995, p. 96): “[...] O vivente humano prolonga, de modo mais ou menos lúcido, um efeito espontâneo, próprio da vida, para lutar contra aquilo que constitui um obstáculo à sua manutenção e ao seu desenvolvimento tomado como normas. [...] o fato de reagir por uma doença a uma lesão, a uma infestação, a uma anarquia funcional, traduz um fato fundamental: é que a vida não é indiferente às condições nas quais ela é possível, que a vida é polaridade e por isso mesmo, posição inconsciente de valor, em resumo, que a vida é, de fato, uma atividade normativa. Em filosofia, entende-se por normativo qualquer julgamento que aprecie ou qualifique um fato em relação a uma norma mas essa forma de julgamento está subordinada, no fundo, àquele que institui as normas. No pleno sentido da palavra, normativo é o que institui normas. E neste sentido que propomos falar sobre uma normatividade biológica."
}

sidera os processos de mudança dos sujeitos nas práticas de produção de saúde: "sujeitos sociais, atores concretos e engajados em práticas locais, quando mobilizados, são capazes de, coletivamente, transformar realidades transformando-se a si próprios neste mesmo processo. Assim, as ações de humanização são pensadas como "estratégia de interferência nestas práticas" [práticas de saúde] (BENEVIDES; PASSOS, p. 391). Os princípios que norteiam essas ações e a partir dos quais a PNH se desdobra enquanto política pública são três: transversalidade - diz respeito ao grau de abertura à alteridade, ou seja, ao aumento da comunicação, alargando os saberes já instituídos; indissociabilidade entre atenção e gestão, indicando que os modos de cuidar são inseparáveis dos modos de operacionalizar esse cuidado; e protagonismo, corresponsabilidade e autonomia dos sujeitos e dos coletivos, através dos quais se reconhece a parcela de responsabilidade dos sujeitos implicados no processo de gerir e cuidar.

Quanto ao método, a PNH salienta um caminho de tríplice inclusão: a dos diferentes sujeitos (com as rodas de conversa), a dos fatores que dissolvem modelos tradicionais de atenção e gestão (com análise coletiva dos conflitos) e a do coletivo (a partir do fomento ao funcionamento por redes). As diretrizes expressam o método da inclusão, dentre as quais destacamos: Clínica Ampliada, Cogestão, Acolhimento, Valorização do trabalho e do trabalhador, Defesa dos direitos do usuário, Fomento das 
grupalidades, coletivos e redes e Construção da memória do "SUS que dá certo". Sobre os dispositivos, a PNH os define como modos de operacionalizar as diretrizes. Como exemplos podemos citar: equipe transdisciplinar de referência; projeto terapêutico singular; apoio matricial, colegiados gestores, acolhimento com classificação de risco, ouvidorias, visita aberta/ampliada, grupos de trabalho de humanização (GTHs), sistemas de escuta qualificada, dentre outros.

Diante da necessidade de provocar inovações nas práticas gerenciais, nas práticas de produção de saúde, e de experimentar novas formas de organização dos serviços, novos modos de produção e circulação de poder, surge um programa do governo federal - a Residência Integrada Multiprofissional, a partir da promulgação da Lei $n^{\circ}$ 11.129 , de 2005 - orientado pelos princípios e diretrizes do SUS, abrangendo profissões da área da saúde que atuam conjuntamente na atenção e na gestão, reafirmando a proposta da Clínica Ampliada entendida como "ferramenta de articulação e inclusão dos diferentes enfoques [biomédico, social e psicológico] e disciplinas" (BRASIL, 2010a, p. 10) no cuidado do usuário e do serviço.

A Residência Multiprofissional (REMU), definida como modalidade de ensino de pós-graduação lato sen$s u$, visa a uma nova ética do cuidado na medida em que contempla a concepção ampliada de saúde ao considerar a diversidade e o sujeito enquanto ator social responsável por seu processo de vida, inserido num ambiente social, político e cultural (BRASIL, 2009a, p. 1). No Hospital Universitário da Universidade Federal de Sergipe (HU/ UFS), a Residência Integrada Multiprofissional em Saúde foi criada há cerca de quatro anos, contemplando sete profissões (psicologia, serviço social, farmácia, nutrição, fisioterapia, cirurgião-dentista, enfermagem). No referido hospital atuam profissionais de dois programas: Saúde do Adulto e do Idoso e Epidemiologia. É importante ressaltar que, durante três meses, a inserção ocorreu, complementarmente, na atenção primária, uma maneira de incorporar a proposta da integralidade ${ }^{2}$ do SUS, ao propor - na esfera da continuidade da assistência - o contato com os diferentes níveis de complexidade, contribuindo para a compreensão na prática de suas articulações. No cenário de práticas destacado, as ações estiveram voltadas para a prevenção e promoção da saúde, com a formação de grupos de usuários e intervenções na sala de espera, onde eram realizados debates e ações educativas relacionados ao estilo de vida da população, suas condições sociais, econômicas e ambientais.

Nesse percurso de consolidação da REMU surgiram avanços, mudanças de rumos, novas questões que demandaram dos residentes uma formulação/reformulação de suas práticas. Durante a inserção no cotidiano do hospital, paulatinamente, a partir do diálogo entre os profissionais, foram criados dispositivos consonantes com a Política Nacional de Humanização, em virtude da necessidade de articulação entre esta política pública de saúde e as ações da Residência Multiprofissional. Como já

\footnotetext{
${ }^{2}$ Novamente abordaremos o princípio da integralidade no tópico deste artigo: "O Projeto Terapêutico Singular (PTS): a integralidade na assistência".
}

afirmado acima, o SUS necessita da criação permanente de estratégias no âmbito das práticas para sua efetivação. Nesse sentido, consideramos que a Residência Multiprofissional se constituiu, ainda que em um movimento embrionário, como uma estratégia potencial.

Partindo dessas formulações, este trabalho teve como objetivo acompanhar e analisar processos de criação de dispositivos consonantes com a Política Nacional de Humanização (PNH) no Hospital Universitário (HU/UFS), a partir das intervenções produzidas pela Residência Multiprofissional. A proposta, portanto, foi a de identificar nas práticas da Residência Multiprofissional as orientações gerais da Política Nacional de Humanização, bem como seus dispositivos, analisando, ainda, possíveis efeitos produzidos no contexto institucional.

\section{A cartografia como metodologia}

A pesquisa realizada, de cunho qualitativo, buscou desenhar os processos de mudanças a partir da experiência do pesquisador em contato com o campo - nesse caso, a residente de psicologia, em seu período de atuação -, seja através de sua própria experiência, seja através das experimentações de outros residentes trazidas ao longo do trabalho e que estão presentes em depoimentos orais ou em relatórios pedagógicos. O ponto de apoio, portanto, é a experiência como residente. Nesse sentido, o método escolhido foi a Cartografia: "um método formulado por Gilles Deleuze e Félix Guattari que visa acompanhar um processo, e não representar um objeto. Em linhas gerais, trata-se sempre de investigar um processo de produção" (KASTRUP, 2009, p. 32).

O método cartográfico se constitui como proposta metodológica resultante de críticas ao modo tradicional de se fazer ciência, tal como afirmado por Escóssia e Tedesco (2009, p. 99):

Restritas à dimensão das formas, as metodologias tradicionais de pesquisa não conseguem apreender a marca mais genuína da realidade, seu processo contínuo de individuação, ou se preferirmos, seu processo de criação. O desafio da cartografia é justamente a investigação de formas, porém, indissociadas de sua dimensão processual, ou seja, do plano coletivo das forças moventes.

Além da dimensão processual, as autoras destacam, na cartografia, a dimensão coletiva da realidade, relacionando ambas ao plano das forças. Desse modo, concebe-se um contexto em intenso movimento e em constante mudança, onde sujeito e objeto são engendrados - e co-engendrados (KASTRUP, 2009), o que nos permite conceber subjetividade e objetividade como efeitos de uma processualidade. Nossos objetos de pesquisa social, embora se apresentem como formas, são efeitos de processos em que estão em jogo inúmeras forças históricas, econômicas, culturais e afetivas, produtoras de agenciamentos. ${ }^{3}$

A tarefa do cartógrafo, proposta para a realização deste trabalho, consiste em acompanhar processos de mudanças, ao mesmo tempo em que imprime um caráter

${ }^{3}$ Noção mais ampla do que as de estrutura, sistema, forma, processo, montagem, etc. Um agenciamento comporta componentes heterogêneos, tanto de ordem biológica quanto social, maquínica, gnosiológica, imaginária (GUATTARI, F; ROLNIK, S., 2005, p. 381). 
interventivo. Ao delinear uma certa "realidade", apontando para os limites e insuficiências de um modo atual de significações, catalisa processos de mudança e transformação, caracterizando o que Virgínia Kastrup ${ }^{4}$ afirmou como indissociabilidade entre pesquisa e intervenção e como dupla intervenção pesquisador-pesquisados.

$\mathrm{O}$ método cartográfico neste trabalho configura-se, assim, como importante ferramenta de acompanhamento dos processos inventivos/interventivos da Residência Multiprofissional relacionados à Política Nacional de Humanização.

\section{Uma proposta para tornar realidade a Clínica Ampliada}

No plano da saúde coletiva, ampliar a clínica significa construir processos de saúde que articulem e incluam diferentes enfoques e disciplinas, pois é sabido que as pessoas não se limitam às expressões de suas doenças. Vejamos a afirmação de Dário F. Pasche (2005, p. 22) sobre a ampliação do conceito de saúde nesse campo: “A saúde coletiva se produz, então, como um 'lugar-síntese' do encontro de uma multiplicidade de fatores de distintas naturezas". Isto implicaria empregar "um olhar menos instrumental, mais direcionado à complexidade de sua dimensão múltipla de sujeito" (PASCHE, 2005, p. 28), desnaturalizar a supremacia do fator biológico sobre a dimensão social do sujeito (o que não significa dizer que o biológico não tem um papel crucial no que se entende por saúde) e redefinição do entendimento sobre o processo saúde-doença, levando a reconhecer a multicausalidade e uma concepção ecológica - esta, por sua vez, afirma que o homem, o agente etiológico e o ambiente guardam uma relação dinâmica entre eles e são potencialmente importantes no processo saúde-doença. Ou seja, não é com o ataque direto à doença que se produz saúde, mas com o atendimento às necessidades biológica, econômica, social e psicológica dos sujeitos.

A partir desse entendimento, evidencia-se a complexidade inerente ao campo da clínica, já que esta deve incluir dimensões da realidade dos sujeitos e dos serviços de saúde que não cabem nos protocolos tradicionais e nos modelos de diagnósticos e terapêuticos centrados exclusivamente na doença. Diante da necessidade de efetivação de tal compreensão, durante a inserção da Residência Multiprofissional, tornou-se urgente a articulação entre as diferentes profissões à medida que as equipes discutiam os casos clínicos e propunham possibilidades terapêuticas para os usuários do Hospital Universitário da UFS (HU/UFS). A residência na oportunidade era representada por oito equipes com sete profissionais de áreas diferenciadas, atuando em diferentes setores do hospital, ambulatório e atenção primária, em sistema de rodízio, durante o período de dois anos.

É importante destacar que, para a efetivação da Clínica Ampliada, fez-se necessário que as equipes compreendessem a diferença entre uma atuação interdisciplinar e uma atuação multidisciplinar. De acordo com Almeida Filho (2005), a multidisciplinaridade pressupõe que um conjunto de disciplinas trate de uma determinada questão, problema ou assunto, sem que os profissionais implicados estabeleçam entre si efetivas relações no campo técnico ou científico. Diferentemente, a interdisciplinaridade exige uma política compartilhada de saberes, uma integração, gerando uma aprendizagem mútua e soluções a partir da recombinação das diferentes disciplinas.

No cotidiano do HU, a multidisciplinaridade mostrou-se insuficiente para uma atuação resolutiva, pois era preciso, dentre outras ações, que os profissionais das equipes discutissem de forma interdisciplinar com vistas à produção de uma compreensão ampliada do processo saúde-doença. Nesse sentido, os residentes propuseram à coordenação da Residência Multiprofissional a criação de espaços de discussão entre os profissionais residentes, como componente da estrutura de horários da referida especialização. Em tais espaços, vários aspectos sobre o adoecimento eram sinalizados, tais como: a dimensão propriamente biológica, as correlações de forças na sociedade (econômicas, culturais, etc.) e a dimensão afetiva. A partir da compreensão dos casos, foram construídas propostas terapêuticas compartilhadas, tanto entre a equipe como entre equipe e usuário. Essa experiência de compartilhamento tornou a atuação mais resolutiva, uma vez que o cuidado foi estabelecido de forma integral. É importante destacar que, embora a proposta surgisse entre os residentes, alguns membros das equipes efetivas dos setores demonstraram, pouco a pouco, interesse pela proposta, participando de alguns encontros. Esses profissionais eram convidados pelos residentes para participar das reuniões. Inicialmente foram muitos os desafios, pois alguns entendiam que esse momento em nada melhoraria o funcionamento do serviço. No entanto, à medida que as discussões dos casos e das questões relativas ao trabalho tornavam o cuidado mais resolutivo, as participações foram ampliadas.

Nesses mesmos espaços, dificuldades trazidas pelos profissionais refletiam, na maior parte dos casos, problemas relativos aos processos de trabalho, conflitos e dificuldade de atuação em virtude da necessidade do auxílio de outras perspectivas para a compreensão do adoecimento, tornando cada vez mais necessária a comunicação transversal das equipes. Nesse sentido, a Residência Multiprofissional, por meio da interdisciplinaridade, trouxe para o Hospital a necessidade de se estabelecer uma comunicação mais efetiva entre os profissionais, residentes ou não, para além das anotações em prontuários.

Podemos dizer que a análise coletiva do cotidiano do hospital, ao dar visibilidade aos limites de uma certa prática clínica e às possibilidades, mesmo que pequenas, de ultrapassamento destes limites, produziu nas equipes um movimento de experimentação da clínica ampliada. 


\section{O acolhimento como estratégia nas ações de saúde}

O acolhimento, reconhecido ao mesmo tempo como diretriz e dispositivo da $\mathrm{PNH}$, diz respeito aos processos constitutivos das práticas de produção de saúde que implica comprometimento da equipe com os usuários dos serviços. Especificamente, enquanto dispositivo, constitui-se como uma ferramenta tecnológica relacional que realiza uma escuta qualificada do usuário, possibilitando analisar e qualificar a demanda de saúde. É, portanto, uma ação técnico-assistencial pautada em "parâmetros técnicos, éticos, humanitários e de solidariedade, levando ao reconhecimento do usuário como sujeito e participante ativo no processo de produção da saúde" (BRASIL, 2010a, p. 18).

$\mathrm{O}$ acolhimento como diretriz deve ser entendido como uma postura ética, que não exige um espaço ou local, pois não implica um profissional ou uma hora específica para realizá-lo, mas pressupõe "compartilhamento de saberes, angústias e invenções, tomando para si a responsabilidade de "abrigar e agasalhar" outrem em suas demandas, com responsabilidade e resolutividade sinalizada pelo caso em questão" (BRASIL, 2009b, p. 17).

As equipes da Residência Multiprofissional realizavam o acolhimento dos usuários de formas diferenciadas: primeiro no ambulatório das clínicas médicas do Hospital Universitário; depois no internamento, nas Clínicas Médicas e Cirúrgicas. No ambulatório havia uma sala onde os residentes, juntamente com o usuário, construíam uma rede de diálogos e formulavam propostas terapêuticas a partir das queixas, medos e expectativas apresentados, da identificação dos riscos e vulnerabilidade, sempre valorizando a participação do usuário no processo. No final de cada encontro era feito um registro com as principais informações, com o objetivo de informar à equipe de residentes, a ser alocada no próximo rodízio, a demanda de saúde produzida e os encaminhamentos propostos. É importante destacar que o acolhimento não se esgotava nesse primeiro contato com o usuário. Nesse sentido, podemos diferenciar acolhimento de triagem, pois ele não era tido como uma etapa de um processo, mas uma ação que ocorria em todos os momentos e locais dos serviços de saúde onde a residência estava presente, tendo em vista a concepção ética da diretriz.

Tal proposta de comprometimento da equipe multiprofissional com o usuário do serviço ambulatorial surgiu a partir das discussões realizadas entre os residentes, assim como em encontros no formato de rodas de conversa, onde eram realizadas essas trocas entre os profissionais. A ideia era a de que esses momentos se configurassem como prática componente do quadro de atividades da Residência Multiprofissional.

Entre os profissionais efetivos do serviço, a denominação acolhimento era tradicionalmente atribuída ao processo de triagem realizado pelo profissional de enfermagem, ou à recepção e fornecimento de informações sobre o funcionamento do serviço, sendo realizado principalmente pelo profissional de Serviço Social. Enquanto postura, observávamos o acolhimento nas ações pontuais de alguns profissionais do HU; no entanto, sabíamos da diferença que poderia produzir nos processos de trabalho e na atenção ao usuário se ocorresse em todos os setores e momentos do serviço.

A partir da inserção da Residência Multiprofissional, esse processo foi disparado de maneira interdisciplinar, ampliando a comunicação e envolvimento dos profissionais responsáveis pelo cuidado. No ambulatório, a implantação ocorreu através de parcerias entre os residentes e os profissionais médicos, em que era acordado que antes do atendimento seria feito um convite ao usuário para que este participasse de um acolhimento realizado pela equipe multiprofissional. Em relação a outras áreas, não existia marcação ou organização de atendimentos em agenda disponível na recepção, já que esse tipo de atendimento era restrito às consultas médicas, por isso o acordo foi estabelecido com a área médica. Embora houvesse esse acordo, alguns acolhimentos não eram finalizados ou sequer iniciados, pois houve resistências por parte de alguns profissionais à ideia de um cuidado interdisciplinar, pelo fato de este, até então, ser considerado nessa instituição algo quase exclusivamente médico. No entanto, paulatinamente, os profissionais efetivos, alunos e residentes da Medicina reconheciam os efeitos positivos do Acolhimento Multiprofissional, alguns interagindo diretamente com a equipe, outros preferindo dialogar através dos prontuários.

No ambulatório, portanto, podemos dizer que, de uma maneira micropolítica, ocorreu uma inversão no funcionamento institucional: se antes o profissional da área médica recebia esse usuário e realizava os encaminhamentos para profissionais de diferentes áreas, após a implantação do acolhimento multiprofissional, os profissionais, juntamente com os usuários, identificavam inicialmente algumas demandas, e só depois encaminhavam para a consulta médica.

Durante o internamento dos usuários também ocorria um acolhimento, quando as equipes realizavam seus atendimentos individuais ou por meio de dispositivos criados por elas, a saber, as visitas e altas multiprofissionais. Durante as visitas multiprofissionais, o acolhimento funcionava de forma semelhante ao ambulatório, ou seja, era realizado no encontro entre residentes de diferentes áreas, e os usuários, tendo contado, em alguns momentos, com a participação de profissionais efetivos que aderiram à proposta - o que não ocorreu no ambulatório. No internamento o desafio era produzir maior participação dos usuários, pois a estrutura e o funcionamento hospitalar ainda reforçavam, em grande parte, a passividade deles no próprio cuidado. Podemos associar tal fato à característica histórica de disciplinarização do hospital, ${ }^{5}$ onde a organização produz o assujeitamento dos indivíduos ao produzir a crença de que os profissionais são os únicos detentores do saber. Quanto às altas multiprofissionais, a equipe acolhia o usuário ao responsabilizar-se pelas orientações de cuidado no pós-alta, além de, quando fosse o caso, orientá-lo para a continuidade da assistência em outros serviços.

${ }^{5}$ Sobre a disciplinarização, ver Foucault (2006, p. 107-109). 
As visitas e as altas multiprofissionais no HU foram propostas pela Residência Multiprofissional, a partir do entendimento da Clínica Ampliada. No que se refere às visitas multiprofissionais, tivemos relatos de usuários que enfatizaram a importância desse dispositivo, pois através dele podiam conhecer a equipe e a função de cada profissional responsável por seu cuidado, além de participar ativamente do processo. Sabemos da importância desses relatos, uma vez que o cotidiano dos Hospitais Universitários, pela característica de ser um hospital-escola, é permeado por uma rede complexa de profissionais, professores e alunos envolvidos na atenção ao usuário, ocasionando, por vezes, um cuidado fragmentado.

A alta multiprofissional foi o dispositivo que mais enfrentou as barreiras do instituído. No contexto do HU, geralmente as altas eram realizadas quase exclusivamente por critérios estabelecidos pelo saber médico. Havia um tipo de problema muito frequente: muitos usuários retornavam ao hospital, principalmente por não serem realizados, de forma devida, os encaminhamentos para outros serviços de saúde, ou não terem recebido orientações que considerassem as diferentes dimensões do adoecimento. Após a implantação da alta multiprofissional, a equipe de residentes interferiu em alguns casos clínicos. Destacamos aqui um dos casos, quando essa equipe identificou a necessidade de acompanhamento dos residentes para efetivar o processo de alta. Assim que era realizada essa avaliação, os residentes discutiam com os profissionais a importância das avaliações e encaminhamentos de diversas áreas, além da área médica. Nesse sentido, além da alta médica, tornou-se relevante a avaliação multiprofissional para finalizar o cuidado e liberar o usuário. Obviamente, essa proposta produzia conflitos entre residentes (área médica e multiprofissional) e profissionais, registrados principalmente em prontuários, além de casos levados à diretoria do hospital, motivados justamente pela discordância em relação às interferências da Residência Multiprofissional que, naquele momento, modificava uma prática institucionalizada.

Entendíamos, como residentes, que era estratégico produzirmos enfrentamentos, e ao mesmo tempo sermos propositivos, a fim de gerar comprometimento e corresponsabilização da equipe com o cuidado dos usuários. A proposta do acolhimento, através dos momentos compartilhados no Ambulatório, bem como nas visitas e altas multiprofissionais do internamento, mostrou-se um importante dispositivo para a obtenção desses objetivos.

O acolhimento possui relevância de ordem ética, estética e política. Ética, na medida em que se propõe a comprometer-se com o reconhecimento do outro, ao acolhê-lo em suas diferenças, alegrias, dores, modo de perceber a vida, entre outros aspectos. Estética, "porque traz para as relações e os encontros do dia a dia a invenção de estratégias que contribuem para a dignificação da vida e do viver e, assim, para a construção de nossa própria humanidade" (BRASIL, 2010a, p. 11). E política, pois há um comprometimento coletivo que pressupõe uma potencialização do protagonismo dos sujeitos. Tudo isso favorece a relação de confiança e o comprometimen- to entre o usuário com a equipe de assistência e o próprio serviço de saúde e coopera para "a promoção da cultura de solidariedade e para a legitimação do sistema público de saúde" (BRASIL, 2010a, p. 4).

\section{O Projeto Terapêutico Singular (PTS): a integralidade na assistência}

No intuito de elaborar propostas e ações terapêuticas consonantes com a Política Nacional de Humanização, a Residência Multiprofissional elaborava, juntamente com o usuário, seu Projeto Terapêutico Singular. O PTS é um dispositivo voltado para coprodução de saúde e de sujeitos autônomos, vinculado a algumas diretrizes da $\mathrm{PNH}$ como Acolhimento, Clínica Ampliada e Cogestão. Resulta da discussão coletiva entre uma equipe e um sujeito com alguma demanda de cuidado em saúde.

No HU, durante a realização do PTS, a equipe buscava, juntamente com o usuário, identificar problemas e relações com o adoecimento, além de potencialidades que auxiliariam no cuidado. Esse momento era pautado por uma abordagem biopsicossocial do processo saúde-doença e pela transversalidade na comunicação - ou seja, uma produção do "comum", no qual todos podiam comentar ou propor encaminhamentos. Por isso não eram aplicados questionários ou mesmo seguido protocolos. Nesse espaço comum, as propostas de curto, médio e longo prazos eram apresentadas e negociadas com o usuário, podendo mesmo ser recusadas por este. No caso de uma recusa, a equipe reforçava as informações necessárias a fim de excluir que a mesma ocorresse por desconhecimento do problema e para houvesse uma corresponsabilização pela decisão. Feitos os encaminhamentos para os atendimentos individuais, durante o acompanhamento do usuário, eram propostas reavaliações dos casos para definir mudanças de rumos quando necessárias.

Salientamos, com a efetivação do PTS, um dos princípios constitucionais do SUS: a integralidade. Se por um lado o conceito reforça a importância do direito de acesso do usuário a todas as esferas de atenção em saúde - preconiza, portanto, que as ações assistenciais, em todos os níveis de complexidade (atenção primária, secundária e terciária), estejam articuladas de tal modo que permitam ao usuário o acesso a rede de serviços -, por outro lado a integralidade diz respeito, ainda, tal como ressaltamos com a prática do PTS, à proposta de considerar o sujeito em suas indissociáveis dimensões biopsicossociais (abordagem integral do ser humano), suplantando, com esse exercício, a fragmentação do cuidado. ${ }^{6}$

Realizar o projeto terapêutico de cada usuário não era tarefa simples. Em virtude da grande demanda, nem sempre foi possível construí-lo para todos que procuravam o hospital, porém as equipes priorizavam a elaboração de PTS nos casos mais complexos.

Por meio da concepção de Clínica Ampliada, da proposta do Acolhimento e do Projeto Terapêutico, relevantes efeitos foram observados pela equipe. $\mathrm{O}$ usuário estabelecia com os residentes uma relação de confiança ${ }^{6} \mathrm{O}$ conceito de integralidade foi abordado a partir da discussão presente em: "HumanizaSUS: documento base para gestores e trabalhadores do SUS" (BRASIL, 2010b, p. 62-63).

Fractal, Rev. Psicol., v. 30 - n. 3, p. 322-329, 2018 
importante para a continuidade do tratamento. O entendimento da complexidade do sujeito por parte da equipe lhe permitia perceber que ações pontuais e isoladas não favoreciam um plano de cuidado resolutivo.

\section{Política de Humanização e Cogestão como reinvenção dos processos institucionais}

Durante o primeiro ano de atuação na Residência Multiprofissional do HU, os residentes experimentaram dificuldades de inserção e consolidação do projeto de humanização do serviço. Alguns setores do hospital apresentavam problemas em relação aos processos de trabalho, principalmente aqueles setores onde existia alta rotatividade de usuários, como por exemplo a Clínica Cirúrgica. Tais problemas repercutiam no atendimento oferecido à comunidade. Ao mesmo tempo, as equipes discutiam possibilidades de mudanças, além de atuarem efetivamente com alguns dispositivos salientados nas discussões anteriores.

Porém, se por um lado pudemos observar avanços no que tange à assistência ao usuário, com a inserção da Residência Multiprofissional, por outro lado havia a necessidade de disparar mudanças nos modos de gerir e pensar o trabalho. Considerando o modelo de gestão institucionalizada na época, necessitava-se de uma reinvenção dos processos de trabalho. Aliás, a própria PNH salienta a importância da relação entre os modos de cuidar e os modos de gerir o trabalho, definindo-os como inseparáveis, pois as estratégias de organização do trabalho interferem de forma decisiva no tipo de cuidado oferecido.

De acordo com o Ministério da Saúde, para operar mudanças no ambiente institucional é de suma importância a existência de espaços de aproximação e compartilhamento de tensões e dificuldades do cotidiano do trabalho: "acolher e debater as diferenças, os sonhos de mudança e buscar, por meio da análise e de negociação, propostas que permitam, de fato, que as melhorias desejadas aconteçam (BRASIL, 2004, p. 6).

Nesse sentido, a Residência Multiprofissional, juntamente com um professor da área de Medicina, formulou um projeto de intervenção para uma das clínicas do Hospital Universitário, escolhida por ser uma área onde as dificuldades quanto à humanização estavam mais evidentes. A Clínica Cirúrgica desse hospital atende aos usuários com riscos potenciais, tornando-se clara a necessidade de uma atuação baseada na proposta da PNH.

Considerando-se algumas dificuldades discutidas em equipe quanto aos processos de cuidado com esses usuários, foi definida pela coordenação do Programa de Residência, em colaboração com a equipe e o professor médico do setor, que a Clínica Cirúrgica seria cenário de atuação das equipes que estavam no seu segundo ano de residência. Dessa forma, três equipes realizaram esse projeto.

Após algumas reuniões para exposição e discussão da proposta, percebeu-se que antes de realizar qualquer intervenção seria preciso compreender como estavam instituídos os processos de trabalho e quais eram as principais fragilidades, potencialidades, limitações e contradições deste setor, que interferiam em um cuidado mais integral, resolutivo e humanizado. Diante dessa compreensão, o projeto intitulou-se "Análise dos Processos de Trabalho da Clínica Cirúrgica do HU/UFS”.

Inicialmente foram discutidas diversas propostas de metodologia de trabalho, além da elaboração de um projeto estruturado e organizado. Como ponto de partida foi sugerida pelo professor uma observação de campo por um período de duas semanas. Foram observados os processos de trabalho que interferiam tanto no cuidado ao usuário e ao acompanhante - compondo a observação geral - quanto no desenvolvimento das atividades de cada profissão da Residência Multiprofissional - compondo a observação de núcleo. Além disso, foram percebidas questões relacionadas às interações interpessoais no setor.

Com o objetivo de analisar coletivamente os processos de trabalho da clínica, as equipes sugeriram a realização de grupos focais como segunda etapa da metodologia, considerando os profissionais envolvidos na assistência como atores essenciais da dinâmica de reflexão. Essa metodologia, além de facilitar a obtenção de visões diferentes sobre uma mesma questão, possibilita o entendimento de ideias partilhadas por pessoas no cotidiano (GATTI, 2005).

O grupo focal é um dos sistemas de escuta qualificada para trabalhadores e usuários citados pela PNH. Define-se como uma técnica de obtenção/produção de dados entre pessoas que compartilham um traço em comum. Segundo Onocko-Campos e Furtado (2006, p. 1058), o grupo focal permite "a apreensão do que pensam os participantes, mas também do porquê eles pensam de determinada forma". Além disso, possibilita "a observação da interação entre seus componentes e os diferentes graus de consensos e dissensos existentes" (ONOCKO-CAMPOS; FURTADO, 2006, p. 1058).

Os grupos foram realizados com usuários, acompanhantes, equipes de enfermagem, residentes da equipe multiprofissional e médica. Através dessa proposta, foi possível experimentar outra diretriz da $\mathrm{PNH}$, a cogestão, definida como "[...] a inclusão de novos sujeitos nos processos decisórios e alteração das tarefas da gestão [...], (BRASIL, 2010c, p. 28). A cogestão incorpora, assim, três funções: a de análise institucional - de contextos e da política; a de formulação e exercício crítico-criativo; e a pedagógica, denominada como Função Paideia, por Gastão Campos (2000).

Para a realização dos grupos focais, cada equipe desenvolveu uma estratégia diferenciada. No nosso caso, a fim de nortear a discussão e facilitar a compreensão das palavras ou temas-chaves expostos pelos participantes, foram elaborados três cartazes. No primeiro foi escrito "O que temos?", onde foram dispostos os principais pontos levantados pelos grupos sobre problemas ou potencialidades encontradas na clínica cirúrgica de acordo com a percepção de cada grupo. No segundo, "O que queremos?" Nesse cartaz foram explicitados desejos e anseios dos participantes para a melhoria da clínica. $\mathrm{O}$ 
último cartaz trazia a questão "O que podemos fazer?". Nesse, os participantes indicavam possibilidades de "fazeres" enquanto profissionais.

Ao analisar os processos de trabalho da Clínica Cirúrgica, as equipes conseguiram realizar um levantamento dos pontos relevantes, de forma que, embora tenham ocorrido entraves, em virtude da rotina institucional, esse levantamento produziu efeitos que favoreceram uma certa ampliação das práticas clínicas no serviço, principalmente no que se refere ao aumento do grau de comunicação e integração entre os profissionais nas atividades cotidianas, proporcionando uma análise coletiva dos processos de trabalho, mesmo que restrita ao âmbito de um serviço/setor.

Pensar o trabalho supõe o entrecruzamento de duas dimensões fundamentais que o atravessa. A primeira diz respeito à forma de relação que produz a repetição; a segunda é a que produz criação, criação de si e de outras formas-trabalho. A relação estabelecida entre os trabalhadores e o trabalho é dada pelo exercício da cognição, ${ }^{7}$ que permite a atuação em dois planos: um interpretativo ou recognitivo, que mantém o trabalhador em suas práticas cristalizadas, submetendo-o ao processo de repetição, e outro, inventivo, que produz uma modalidade de relação diferenciada dos esquemas engessados. Essas duas relações são possíveis porque a cognição atua, por um lado, ao nível do re-conhecimento dos sentidos estabelecidos por normas internas atravessadas que são pelas normas institucionais, e, por outro lado, criando relações na medida em que vão sendo produzidas novas afetações desencadeadas no processo de análise coletiva. Diante desse entendimento, o projeto "Análise dos Processos de Trabalho da Clínica Cirúrgica do HU/UFS” foi uma tentativa de trazer importantes elementos para a discussão e a divulgação de novas iniciativas que visem a um cuidado mais humanizado, contribuindo para a melhoria da assistência.

\section{O Seminário de Humanização como projeto para o fortalecimento da PNH}

O I Seminário de Humanização surgiu da necessidade de fortalecer os projetos que constroem, no cotidiano do trabalho, o "SUS que dá certo". Tal evento, ocorrido em um dia específico, foi idealizado e organizado pelos residentes e teve como eixo teórico-político os princípios, diretrizes e dispositivos da PNH. Preocupou-se em ampliar o debate, promovendo a sensibilização dos residentes no processo de produção de saúde, e, principalmente, objetivou tornar a humanização um movimento inerente às práticas de saúde da Residência Multiprofissional, contribuindo para o fortalecimento do SUS no contexto do Hospital Universitário. Assim, atuou no fomento das grupalidades, coletivos e redes, tal como proposto pela $\mathrm{PNH}$ : a própria experiência do "compartilhar" e "pensar conjuntamente" promove a criação de uma rede viva que sustenta as ações, além de ampliá-las, tornando os esforços individuais mais eficazes em virtude da própria atuação coletiva.

\footnotetext{
Sobre a perspectiva da atividade cognitiva interpretativa e recognitiva, ver discussão em Kastrup (2007, p. 204).
}

Ao produzir uma troca de experiências de ações de humanização - entre os próprios residentes, entre estes e os profissionais convidados de outras instituições e entre o HU e o Ministério da Saúde (por meio da presença de uma consultora da $\mathrm{PNH}$ ) - o seminário propiciou um aprimoramento pedagógico, além de abrir possibilidades de criação de estratégias para lidar com situações que causavam incômodo, insatisfação e adoecimento dos residentes, ao mesmo tempo em que promoveu o debate em torno dos avanços e limitações da Residência Multiprofissional.

À medida que as experiências eram trocadas, deu-se visibilidade a importantes estratégias que poderiam ser adaptadas à realidade do hospital. Após o evento pôde-se observar um certo efeito de contágio nas práticas dos profissionais e residentes. Alguns relataram o quanto o Seminário permitiu a reafirmação de um certo modo de pensar a Humanização nas práticas assistenciais, além de favorecer a criação de dispositivos ao longo dos meses seguintes, como grupos vivenciais entre os usuários e profissionais. O seminário permitiu, ainda, através da troca das experiências cotidianas no ambiente de trabalho, a percepção da indissociabilidade entre atenção e gestão, na medida em que evidenciou a impossibilidade de um cuidado resolutivo sem considerar a forma como nos organizamos para lidar com as demandas do hospital.

\section{Considerações Finais}

Ao cartografarmos a experiência da Residência Multiprofissional do HU, entre os anos de 2012 a 2014, pudemos estabelecer uma clara articulação entre o modo de efetivação desta residência e as propostas da $\mathrm{PNH}$. Sabemos que, para tal política, a humanização não pode ser entendida apenas como mais um "programa" a ser aplicado nos diversos setores da saúde, mas apresenta-se como uma política construída a partir de possibilidades e experiências concretas.

$\mathrm{Na}$ experiência cartografada, as diretrizes da $\mathrm{PNH}$ se efetivaram a partir das afetações nas situações cotidianas de trabalho, possibilitando a invenção e a reinvenção de modos de fazer, mesmo que, em muitos momentos, esse processo de invenção e reinvenção tenha se deparado com fronteiras rígidas dos diferentes saberes/poderes. ${ }^{8}$ Apesar disso, o diálogo entre os profissionais e os modos de trabalho em equipe favoreceu mudanças em uma estrutura hospitalar que ainda mantinha resquícios de um modelo medicocentrista: seguiu caminhos da Clínica Ampliada ao articular e incluir os diferentes enfoques e disciplinas; contribuiu com a cogestão e fomentou as grupalidades quando produziu espaços de análise coletiva dos processos de trabalho, permitindo algumas mudanças nas tarefas de gestão, ainda que no plano informal. Nesse sentido, valorizou o trabalho e o trabalhador ao garantir uma escuta e mapear potencialidades; experimentou o Acolhimento como postura e prática de atenção à saúde; estabeleceu planos de cuidado com os Projetos Terapêuticos.

${ }^{8}$ Lembramos que inicialmente existia uma equipe de sete profissionais; no moe sustentando as práticas preconizadas pelo Sistema Único de Saúde.

Fractal, Rev. Psicol., v. 30 - n. 3, p. 322-329, 2018 
A partir das ações multiprofissionais, foi possível promover processos de mudança nos sujeitos e a partir deles, como também no funcionamento do hospital. Os profissionais efetivos puderam reconhecer paulatinamente a importância da atuação da residência, ao incluírem os residentes nas análises e avaliações de determinados casos clínicos. Porém, esse movimento ainda é bastante incipiente, necessitando de práticas que o afirmem permanentemente. A integração entre a equipe multiprofissional de residentes e a equipe médica, embora tenha avançado, ainda é reconhecida como um problema que afeta diretamente a construção de um cuidado mais efetivo.

Durante os dois anos de experiência, a Residência produziu interferências no ambiente institucional, mas ao mesmo tempo é clara a necessidade de consolidação da PNH no hospital, em diferentes âmbitos e processos: na elaboração de mecanismos de gestão de trabalho mais participativos; na realização de reuniões de equipe interdisciplinares que incluam professores, alunos de graduação, equipes médica e multiprofissional (residentes e profissionais efetivos), uma vez que todos são corresponsáveis pelo cuidado ao usuário; em um modo de organização do serviço que produza práticas mais resolutivas para a saúde do usuário; no exercício do Acolhimento, na elaboração de planos de cuidado.

Para finalizar, gostaríamos de destacar a importância do afeto no trabalho em saúde. A experiência da Residência Multiprofissional aqui analisada tem o seu trabalho afinado com a Política de Humanização, sem absorvê-la enquanto proposta de uma racionalidade científica, ou melhor, de uma política pública que deve ser apenas assimilada. Tal política, em sua própria formação, salientou o papel afetivo-criativo das ações em saúde. Com isso, a aposta é compartilhar um campo de experiências em que todos nós que buscamos produzir saúde e trabalhamos para isso possamos criar formas de atuação a partir do modo como o cotidiano nos toca, exigindo desvios, desnaturalizações, possibilidades outras.

\section{Referências}

ALMEIDA FILHO, N. Transdisciplinaridade e o paradigma pós-disciplinar na saúde. Revista Saúde e Sociedade [online], São Paulo, v. 14, n. 3, p. 30-50, set./dez. 2005. Cross ${ }^{\text {Ref }}$

BENEVIDES, R.; PASSOS, E. Humanização na saúde: um novo modismo? Interface: Comunicação, Saúde e Educação, Botucatu, v. 9, n. 17, p. 389-394, mar./ago. 2005. Disponível em: http://www.scielo.br/pdf/icse/v9n17/v9n17a14.pdf. Acesso em: 30 abr. 2015.

BRASIL, Ministério da Saúde. Humaniza SUS: grupo de trabalho de humanização - GTH. Secretaria-Executiva. Núcleo Técnico de Política Nacional de Humanização. Brasília: Ministério da Saúde, 2004.

BRASIL. Ministério da Educação. Ministério da Saúde. Gabinete do Ministro. Portaria $n^{\circ}$ 1.077, de 12 de novembro de 2009. Dispõe sobre a Residência Multiprofissional em Saúde e a Residência em Área Profissional da Saúde e institui O Programa Nacional de Bolsas para Residências Multiprofissionais e em Área Profissional da Saúde e a Comissão Nacional de Residência Multiprofissional em Saúde. 2009a. Disponível em: $\quad$ http://portal.mec.gov.br/index.php?option=com docman \&view $=$ download \&alias $=15462$-por $-1077-12$ nov2009\&Itemid=30192. Acesso em: 28 mar. 2014.

BRASIL. Ministério da Saúde. Secretaria de Atenção à Saúde. Política Nacional de Humanização da Atenção e Gestão do SUS. Acolhimento e classificação de risco nos serviços de urgência. Brasília: Ministério da Saúde, 2009b. Série B. Textos Básicos de Saúde.

BRASIL. Ministério da Saúde. Acolhimento nas Práticas de Produção de Saúde. Secretaria de Atenção à Saúde. Núcleo Técnico da Política Nacional de Humanização. 2. ed., 5. reimp. Brasília: Ministério da Saúde, 2010a.

BRASIL. Ministério da Saúde. Secretaria de Atenção à Saúde. Núcleo Técnico da Política Nacional de Humanização. HumanizaSUS: documento base para gestores e trabalhadores do SUS. 4. ed. Brasília: Ministério da Saúde, 2010b.

BRASIL, Ministério da Saúde. Secretaria-Executiva. Núcleo Técnico de Política Nacional de Humanização. HumanizaSUS: gestão participativa e co-gestão. Brasília: Ministério da Saúde, 2010c.

CAMPOS, G. W. Um método para análise e co-gestão de coletivos. São Paulo: Hucitec, 2000.

CANGUILHEM, G. O normal e o patológico. Rio de Janeiro: Forense Universitária, 1995.

ESCÓSSIA, L.; TEDESCO, S. O coletivo de forças como plano da experiência cartográfica. In: PASSOS, E.; KASTRUP, V.; ESCÓSSIA, L. (Org.). Pistas do método da cartografia: pesquisa-intervenção e produção de subjetividade. Porto Alegre: Sulina, 2009. p. 92-108.

FOUCAULT, M. O nascimento do hospital. In: Microfisica do poder. São Paulo: Martins Fontes, 2006.

GATTI, B. A. Grupo focal na pesquisa em ciências sociais e humanas. Brasília: Liber Livro, 2005.

GUATTARI, F; ROLNIK, S. Micropolítica: cartografias do desejo. Rio de janeiro: Vozes, 2005.

KASTRUP, V. A invenção de si e do mundo: uma introdução do tempo e do coletivo no estudo da cognição. Autêntica: Belo Horizonte: 2007.

KASTRUP, V. O funcionamento da atenção no trabalho do cartógrafo. In: PASSOS, E.; KASTRUP, V.; ESCÓSSIA, L. da (Org.). Pistas do método da cartografia: pesquisa-intervenção e produção de subjetividade. Porto Alegre: Sulina, 2009. p. 3251.

ONOCKO-CAMPOS, R. T.; FURTADO, J. P. Entre a saúde coletiva e a saúde mental: um instrumental metodológico para avaliação da rede de Centros de Atenção Psicossocial (CAPS) do Sistema Único de Saúde. Caderno de Saúde Pública, Rio de Janeiro, v. 22, n. 5, p. 1053-1062, 2006. Disponível em: http:// www.scielo.br/pdf/csp/v22n5/18.pdf. Acesso em: 15 maio 2015.

PASCHE, D. F. A saúde coletiva: novo campo de reflexão crítica da saúde. In: PASCHE, D.; CRUZ, I. (Org.). A saúde coletiva: diálogos contemporâneos. Ijuí: Unijuí, 2005. Coleção Saúde Coletiva, p. 22-28.

Recebido em: 25 de outubro de 2015 Aceito em: 13 de abril de 2018 